\title{
Animal Tracking Telemetry Circuit using Low Power FM Transmitter
}

\author{
Md. Abdullah Al Hadi
}

Department of Electrical and Electronic Engineering, Rajshahi University of Engineering \& Technology, BANGLADESH

Corresponding Contact:

Email: alhadi@ bubt.edu.bd

\begin{abstract}
There are many rare animals in every countries. Like here in Bangladesh Royal Bengal Tiger is one of them. They need to be protected from being disappeared. Detail information such as their number or their location is also necessary to be collected as they are our national resource. So in this project, a wireless telemetry circuit for animal tracking will be designed, built and tested. The project includes a tone generator, a Low power FM transmitter, and a Spectrum Analyzer. The purpose is to help scientist track and locate animals by sending and receiving radio wave pulses from the FM Transmitter attached to the animal.
\end{abstract}

Key words

Tone Generator, FM Transmitter, Spectrum Analyzer

$12 / 13 / 2016$

Source of Support: None, No Conflict of Interest: Declared

This article is is licensed under a Creative Commons Attribution-NonCommercial 4.0 International License.

Attribution-NonCommercial (CC BY-NC) license lets others remix, tweak, and build upon work non-commercially,

and although the new works must also acknowledge \& be non-commercial.

\section{INTRODUCTION}

Nowadays Bangladesh has only a little more than 100 Royal Bengal tigers living in the Sunderbans forest, far fewer than previously thought. Forestry officials say a survey, using hidden cameras, counted 106 tigers in the wild on the Bangladeshi side of the world's largest mangrove swamp, and about 74 on the Indian side. The figures mark a sharp decline from the 440 animals recorded 10 years ago. Experts say the decline is mainly down to rampant poaching. For this reason an animal tracking telemetry circuit has been introduced in this work. Block diagram of the circuit is given bellow

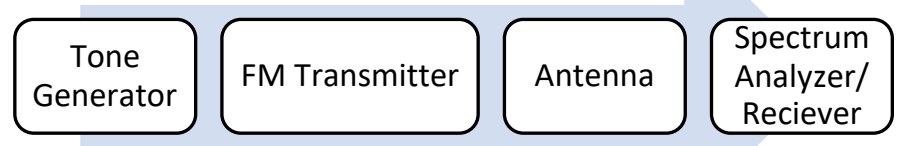

Figure 1: Project block diagram 


\section{Key Design Equations or Relations}

\section{Tone Generator Calculations}

\section{Stage I Tone Generator:}

For a basic 555 Timer, the duty cycle will be range from $50 \%$ to $100 \%$. In order to obtain a low duty cycle signal, a bypass diode will be placed in parallel with the resistor across the trigger input and the discharge input of the timer.

Let Duty cycle $=2 \%$ (0.02) and assume $R_{1}=2 \mathrm{~K}$

$R_{2}=\frac{2 K}{0.02}=100 K$

Next, the desired frequency of 555 Timer will be determined by the timing capacitor between the threshold input and ground.Since the desired frequency for Stage I tone generator is $1 \mathrm{~Hz}$ and $2 \%$ duty cycle, therefore, the tone generator will generate a tone signal that goes on for 0.02 second per every second

$t_{H}=0.693 R_{1} C$

$0.02=0.693(2 K) C$

$C=14.43 u F$

\section{Stage II Tone Generator:}

Since Stage II requires a $50 \%$ duty cycle at $1 \mathrm{KHz}$, the bypass diode is no longer needed. The equations to calculate duty cycle and frequency of this stage will be advised as well.

Duty cyle $=\frac{R_{1}+R_{2}}{R_{1}+2 R_{2}}$

From the duty cycle equation above, the duty cycle will be assumed to be $51 \%(0.51)$ to avoid the cancelation of the equation. For Stage II tone generator to generate a tone signal of $1 \mathrm{KHz}$ and $51 \%$ duty cycle, the HIGH time of the signal will be assumed to be assumed to be $0.51 \mathrm{~ms}$ and LOW time of $0.49 \mathrm{~ms}$.

$t_{1}=0.693\left(R_{1}+R_{2}\right) C$

$0.51 m=0.693(4.7 K+115.150 K) C$

$C=6 n F$

\section{Colpitts Oscillator Calculations:}

Oscillation frequency for a Colpitts Oscillator network will be shown as below:

$f_{O}=\frac{1}{2 \pi \sqrt{L C}}$

The adjustable capacitor of the circle to fining the oscillation frequency can be calculated from the following equation.

$C=\frac{\left(\frac{1}{2 \pi f_{o}}\right)^{2}}{L}$

Inductor (Coil) Calculations:

$L=\frac{d^{2} n^{2}}{18 d+40 l}$

where:

$\mathrm{d}$ is coil diameter (inches)

1 is coil length (inches)

$\mathrm{n}$ is number of turns 
By using available tools in the lab, the diameter of the coil will be fixed at 0.25 inches and the desired inductance for the Colpitts Oscillator network is $80.59 \mathrm{nH}$. After many different trials and testing for most convenient way in designing the coil, the length and number of turns of the coil was determined to be 0.125 inches and 3.5 turns, respectively.

\section{Performance Simulations and Predictions}

\section{Audible Tone Generator}

The goal of the tone circuit is to design and build the telemetry system that has a $1 \mathrm{~Hz}$ pulse modulated with a $200 \mathrm{MHz}$ signal. After designing tone generator with a 555 timer, it was supposed generate a $1 \mathrm{~Hz}$ pulse with a duty cycle between $1-2 \%$. After running in the time domain, it can be seen that the pulses are lasting for a $1-2 \%$ of the time. Once the duty cycle is changed from $1-2 \%$ to $50 \%$, the results clearly show a difference in performance. With a $50 \%$ duty cycle, it was only pulsing half the percent of the time as opposed to the $2 \%$ which was seen before. After Stage I and Stage II was being tested in section IV-A and IV-B, it was time to combine those two audible tone generators together to make it the input signal of the FM transmitter network. The simulation of the Audible tone generator shown has in Figure-2. As can be seen in Figure-2, Stage I and Stage II audible tone generator modulated to create a tone signal, which has the duty cycle of $98 \%$ duty cycle.

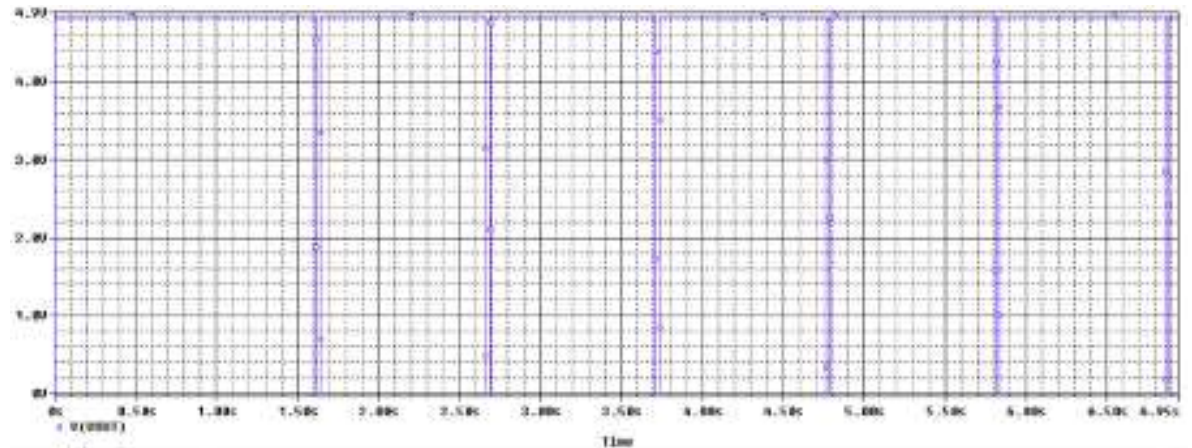

Figure 2: Tone generator final simulation

\section{Low Power Frequency Modulation Transmitter}

After implementing the Low power FM transmitter schematic was tested in Time Domain and AC Sweep. However, the oscillation did not appear at the expected frequency location, therefore, some tuning technique was being done. Knowing that C11 was given as an adjustable capacitor, therefore, this capacitor was being adjusted to different capacitance values to get the oscillate peak to $200 \mathrm{MHz}$.

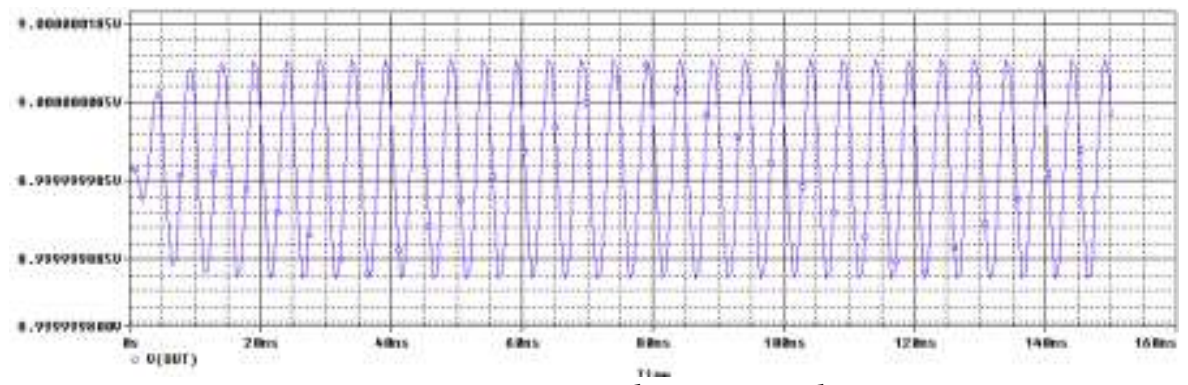

Figure 3: Low power FM transmitter time domain simulation at $200 \mathrm{MHz}$ 


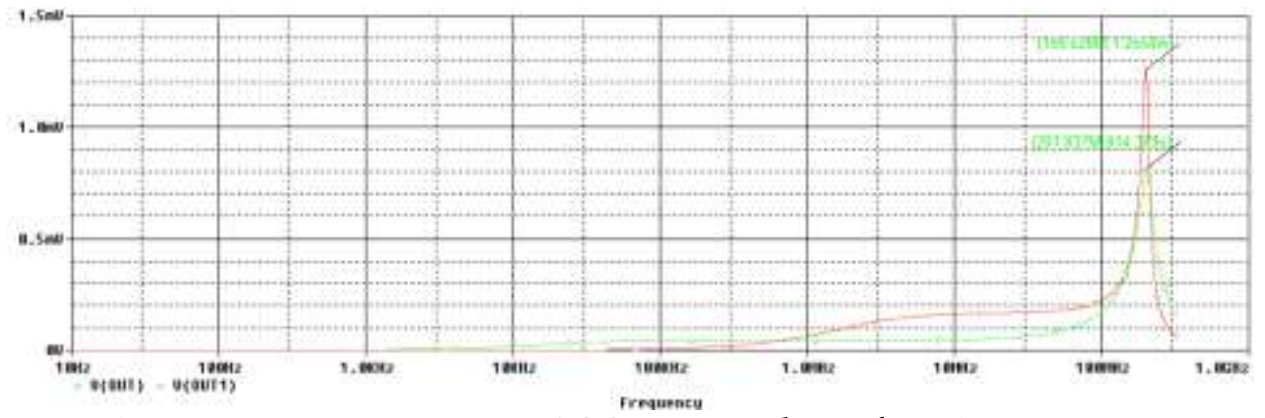

Figure 4: Low power FM transmitter AC Sweep simulation from $10 \mathrm{~Hz}$ to $300 \mathrm{MHz}$

\section{EXPERIMENTAL RESULTS}

\section{Audible Tone Generator}

In the lab, the building and testing for both stage 1 and stage 2 of the tone generator and both circuit performed as expected. The output has a $50 \%$ duty cycle at $1 \mathrm{KHz}$ in the lab. As predicted in PSPICE the simulated results are very similar to the lab results.

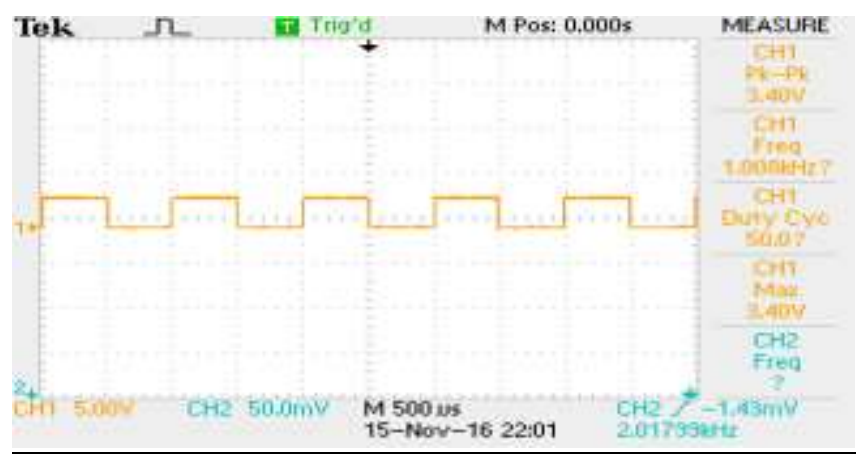

Figure 5: Audible generator stage II simulation

\section{LOW POWER FM TRANSMITTER}

As known that this design will generate an oscillation signal at a very high frequency, therefore, this design cannot be implemented on the solder-less board due to resistances and capacitances inside of the solder-less board that could affect the transmitting output signal. The solution to this issue is to implement the design on a solder board to avoid the loss of power due to the extra existence of resistances and capacitances. After tested the design in Spectrum Analyzer, the receiver shows that the FM transmitting generate an oscillation signal at $305 \mathrm{MHz}$, which is way too big compared to the desired design oscillation frequency, $200 \mathrm{MHz}$. The network was then being implemented on the solder board again, but with different coils value to obtain a closer oscillation frequency of 200 $\mathrm{MHz}$. After tested the second attempt Low power FM transmitter network, the oscillation signal appeared on the Spectrum Analyzer at the frequency of $100 \mathrm{MHz}$, which is much smaller than the required oscillation frequency. The Low power FM transmitter was then being implemented again on the solder-less board with different values of inductance. Then, the Spectrum Analyzer was being used again to read off the value of oscillation frequency. This time, the Spectrum Analyzer gave a better result compared to the last two attempts, $140 \mathrm{MHz}$ oscillation frequency. 


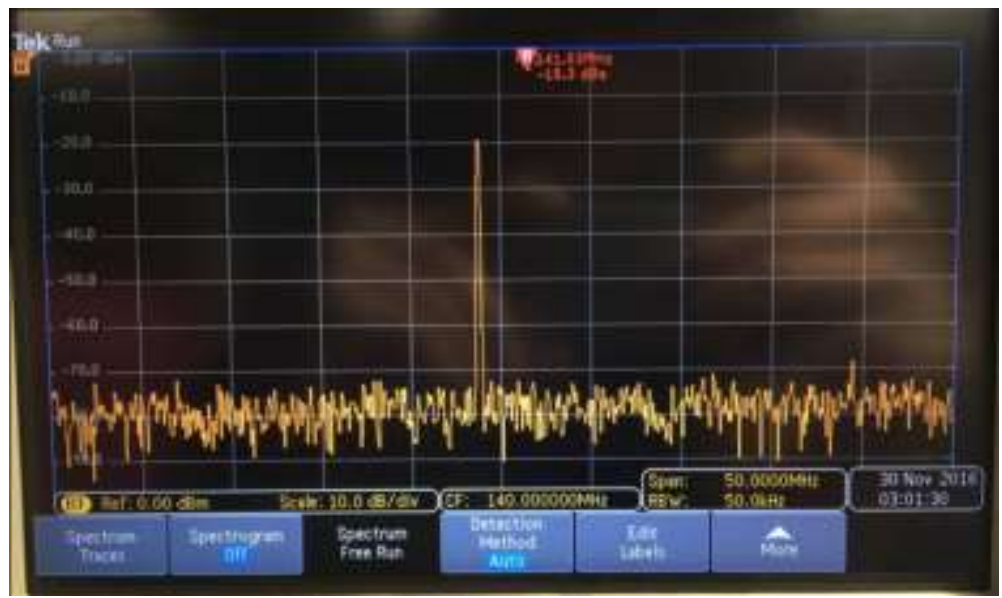

Figure 6: Spectrum Analyzer (FM receiver)

\section{Complete Schematics}

After all the individual aspects were simulated, connecting the tone generator to the FM transmitter and simulated the entire design was next. Demonstrating the FM transmitter carrier signal that is produced by the oscillator and emitter follower circuits, the tone generator signal serves as the input into the carrier signal, and the output of the entire design. Shown below is the PSPICE schematic used in the simulation.

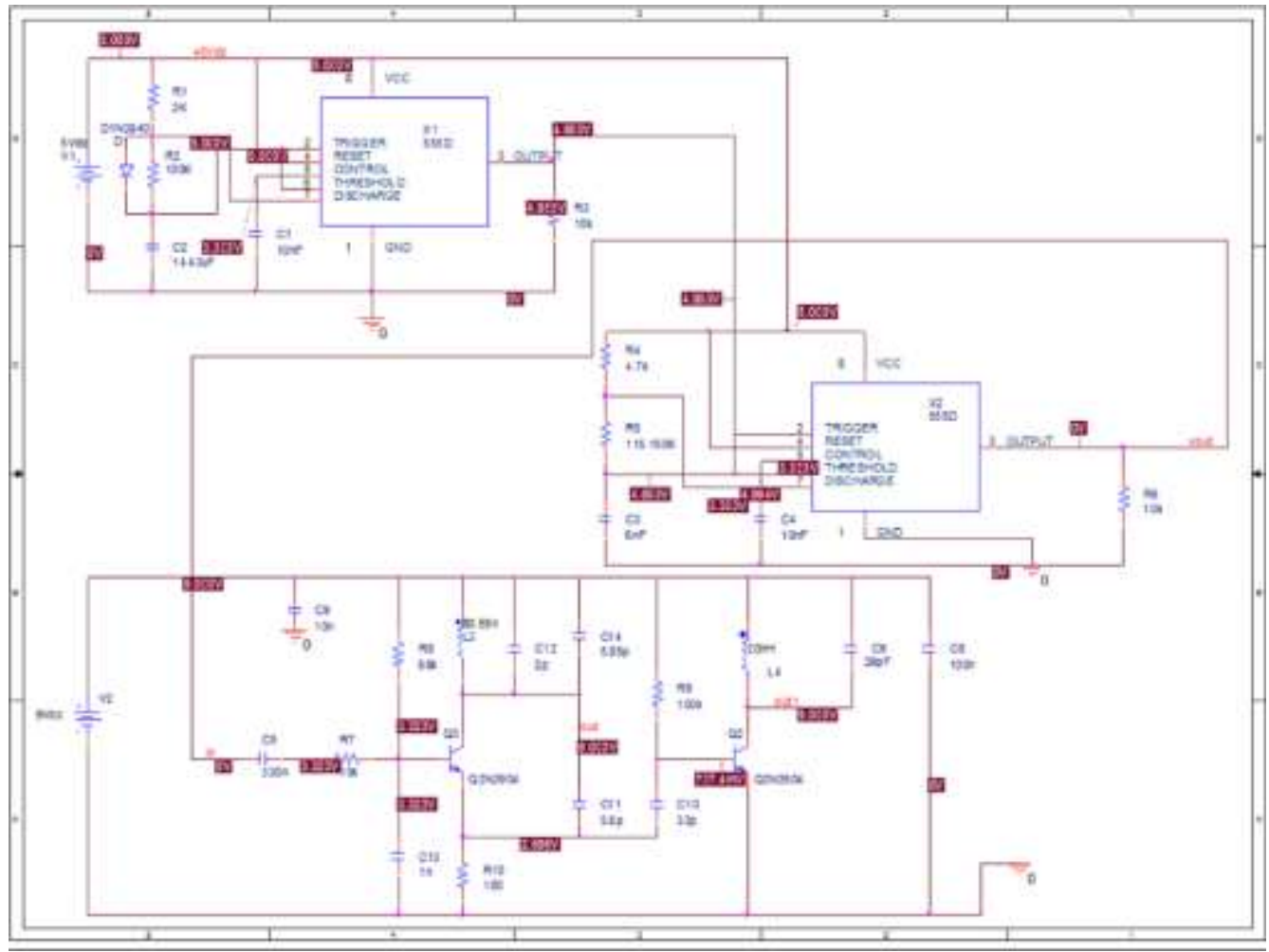

Figure 7: Final schematic in Capture PSPICE 


\section{CONCLUSION}

A systematic approach has been applied to develop the simulation framework. This project uses technique for animal track and locate has successfully worked. As the Radiotelemetry is often used to improve accuracy of classification counts of species which may be classified by means of survey flights. So the next step will be use radio tags are placed on individuals of known sex and age. Classification counts done from aircraft can then be combined with relocation of tagged individuals. Whether or not the tagged animals are visible from the air provides a means of calculating sight ability indices to be used as correction factors for the classification counts.

\section{REFERENCES}

Ahmed AA and Khan W. 2010. Project Process Management Bridge between Project and Information Technology KUET, Abstracts ICMIEE 2010. Khulna, Bangladesh: Faculty of Mechanical Engineering.

Ahmed, R. (2014). Performance Evaluation of Draught Animal Power Cultivator. Asian Journal Of Applied Science And Engineering, 3(3), 369-374.

Akter, N., Rahman, M., \& Akter, S. (2013). Introducing a Phenomenon of Single Junction Multiple Band-gap Solar Cell Compared to Single Junction or Multi Junction Solar Cell to Achieve High Efficiency. ABC Journal of Advanced Research, 2(1), 30-35.

Hosseinimotlagh, S., \& Kianafraz, S. (2014). Studies on the Performance of ITER90H-P Fusion Reactor Considering the D-T and D-3He Fuel in the Steady-state. Asian Journal Of Applied Science And Engineering, 3(1), 99-120.

Kariungi, S. (2014). Determinants of Timely Completion of Projects in Kenya: A Case of Kenya Power and Lighting Company, Thika. ABC Journal of Advanced Research, 3(2), 75-86.

Mahdi, M., Ali, A., \& Hussein, M. (2014). Using Laser-induced Breakdown Spectroscopy Technique to Identify the Low-Carbon Steel in the Industrial Alloy. Asian Journal Of Applied Science And Engineering, 3(2), 244-250.

Peter H. Dana, Walt Fowler and David Hindman. Automated Animal Tracking System: Tracking Elk with Retransmitted Loran C.

Rashid, M., \& Islam, M. (2015). An Innovative Architecture for the Distribution Framework of Smart Grid with Renewable Sources and Power Storage. Asia Pacific Journal Of Energy And Environment, 2(2), 85-92.

Reza, M., Hyder, T., Rahman, M., \& Shahriar, A. (2014). An Overview of Smart Grid Technology with its Present Situation and Anticipation in the Asian Region. Engineering International, 2(2), 79-86.

\section{Websites:}

http://www.bbc.com/news/world-asia-33672602

http://www.daycounter.com/Calculators/Air-Core-Inductor-Calculator.phtml

http://www.electronics-tutorials.ws/waveforms/555_oscillator.html

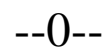

ISSN: 2409-3629

Online Archive Link: https://abc.us.org/ojs/index.php/ei/issue/archive 